GEAP -13643

AEC RESEARCH AND

DEVELOPMENT REPORT
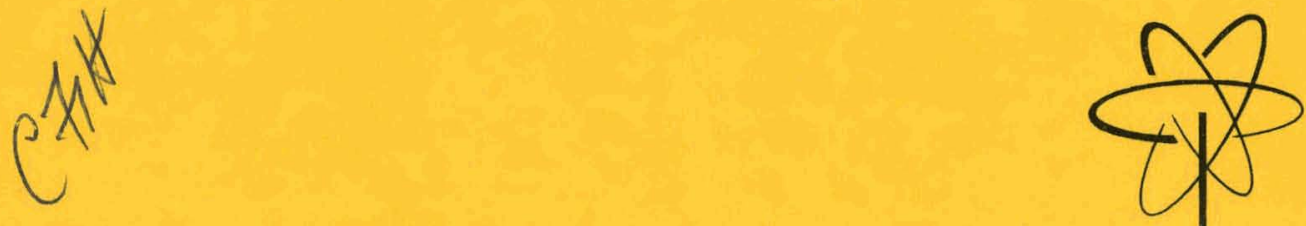

\title{
IMPLICATIONS OF NUCLEAR DATA UNCERTAINTIES TO LMFBR DESIGN
}

P. GREEBLER

B. A. HUTCHINS

C. L. COWAN

U. S. ATOMIC ENERGY COMMISSION

CONTRACT AT(04-3)-189 PROJECT AGREEMENT NO. 10 


\section{DISCLAIMER}

This report was prepared as an account of work sponsored by an agency of the United States Government. Neither the United States Government nor any agency Thereof, nor any of their employees, makes any warranty, express or implied, or assumes any legal liability or responsibility for the accuracy, completeness, or usefulness of any information, apparatus, product, or process disclosed, or represents that its use would not infringe privately owned rights. Reference herein to any specific commercial product, process, or service by trade name, trademark, manufacturer, or otherwise does not necessarily constitute or imply its endorsement, recommendation, or favoring by the United States Government or any agency thereof. The views and opinions of authors expressed herein do not necessarily state or reflect those of the United States Government or any agency thereof. 


\section{DISCLAIMER}

Portions of this document may be illegible in electronic image products. Images are produced from the best available original document. 


\section{NOTICE}

This report was prepared as an account of work sponsored by the United States Government. Neither the United States nor the United States Atomic Energy Commission, nor any of their employees, nor any of their contractors, subcontractors, or their employees, makes any warranty, express or implied, or assumes any legal liability or responsibility for the accuracy, completeness ot usefulness of any information, apparatus product or process disclosed, or represents that its use would not infringe privately owned rights.

\section{IMPLICATIONS OF. NUCLEAR DATA UNCERTAINTIES}

TO LMFBR DESIGN

P. Greebler

B. A. Hutchins

C. L. Cowan

Approved :

\section{1. $6.9 a i l$}

W. E. Baily, Project Engineer

Fast Ceramic Reactor Program
AEC Research and Development Report GEAP-13643

Prepared for the

United States Atomic Energy Commission

Under Contract No. AT (04-3)-189

Project Agreement No. 10

Printed in U.S.A. Available from the

Clearing House for Federal Scientiflc and Tecbnical Information

National Bureau o/ Standards, U.S. Department of Commerce

Springlield, Virginia

Price: $\$ 3.00$ per copy

\section{BREEDER REACTOR DEVELOPMENT OPERATION \\ GENERAL ELECTRIC \\ SUNMYVALE, CALLFORNIA}




\section{NOTICE}

This report was prepared as an account of work sponsored by the United States Government. Neither the United States nor the United States Atomic Energy Commission, nor any of their employees, nor any of their contractors. subcontractors, or their employees, makes any warranty, express or implied, or assumes any legal liability or responsibility for the accuracy, completeness or usefulness of any information, apparatus, product or process disclosed, or represents that its use would not infringe privately owned rights. 
Page No.

\section{ABSTRACT}

1.0

Introduction

1

2.0

Uncertainties in Predicted Core Parameters

4

2.1

Current Prediction Uncertainties and Progress

6 for Improvement

Implications of Uncertainties in Predicted Core Physics Parameters

3.1

Uncertainties in Predicted Shielding Requirements and Radiation Sources

3.2

Plant Shielding

12

4.0

Neutron Source Uncertainties in Fuel Processing

4.1

Effects of Specific Data Uncertainties

Present Uncertainties and Recommended 5-Year

Accuracy Goals - Economic Implications.

4.2 Sources for Estimation of Specific Data. Uncertainties

REFERENCES 
Table No.

Page No.

I

Typical Design Parameters for Early 300 MW(e)

5

and Mature 1000 MW.e) Liquid Metal Fast

Breeder Reactor Cores

II

Uncertainty Ranges in Predicted Physics

7

Parameters of Fast Breeder Power Reactors

Due to Nuclear Data Uncertainties

III

Effects of ${ }^{238} \mathrm{U}$ and ${ }^{239} \mathrm{Pu}$ Uncertainties, on

Predicted Values of Breeding Ratio and

Fissile Pu Inventory

IV

Effects of thcertainties in Fission and Radiative

Capture Cross Sections of Higher Pu Isotopes,

Fission Products, Sodium and Steel on Predicted

Values of Breeding Ratio and Fissile Pu Inventory

V

Current Data Uncertainties and Recommended Accuracy Goals for 1975 
Page No.

Figure 1 Nuclear Reaction Sequences in Pu-U Fuel for 14 Formation of Neutron Source Isotopes 


\section{ABSTRACT}

The current status of uncertainty in predicted physics parameters due to data uncertainties is reviewed and compared with the situation In 1966 and that projected for within the next: two years due to anticipated data improvements. Implications of the uncertainties in the predicted physics parameters to design and operation are discussed for both a near-term LMFBR prototype or demonstration plant ( $300 \mathrm{MW}(\mathrm{e})$ ) and a longer-term large ( $1000 \mathrm{MW}(e)$ ) LMFBR plant. For the nearterm plant, uncertainties in nuclear data require significant allowances to be made in the design and the operating conditions of reactor cores and of shielded reactor plant and fuel processing systems. These allowances result in direct cost increases due to overcesign of components and equipment and reduced core and fuel operating performance. Compromising the allowances has indirect cost implications due to increased risks of failure to meet plant and fuel performance objectivcs, and to satisfy licensed safety requirements. For the longer-term plant, data uncertainties cloud the predictions of the LMFBR reactor economy. While significant improvements in the nuclear data have been made during the past three years, the most important remaining specific data uncertainties are illustrated by their individual contributions to the computational uncertainty of selected physics parameters, and recommended priorities and accuracy requirements for improved data are presented. 


\subsection{INTRODUCTION}

Uncertainties in the nuclear data used in the design analysis of Liquid Metal Fast Breeder Reactors influence both the design and operation of the reactors. The three principle ways in which this influence is felt are the following:

1. Extra margins must be provided in the core design or more restrictive limits imposed on fuel performance objectives, with resultant cost penalty. This is to assure that, in the event of reasonably pessimistic data, fuel and other core materials do not exceed allowed temperatures, requirements for control and reactivity coefficients are satisfied, safety reactivity limits for potential reactivityinsertion mechanisms are not exceeded, and fuel performance meets warrantee requirements.

2. Shielding must be over-designed to allow for reasonably pessimistic shielding data, with associated costs incurred for the extra shielding material and the space required to accommodate the extra material. This involves not only radiation-damage protection for structural components in the reactor vessel and this primary coolant circuit and biological shielding for all personnel access areas within the plant environs, but also shielding of equipment used in the fabrication and the shipment of fuel utilizing recycled fissile material.

3. Planning of long-range fissile material requirements and, hence, fuel costs for all nuclear reactor systems must account for the uncertainties in the predicted fissile doubling times of breeder reactor systems associated with the nuclear data uncertainties.

The first two pertain heavily to near term design activities, such as for an LMFBR demonstration plant, while the third involves the evaluation of future reactor economies. In the case of a specific reactor design, certain contingencies incorporated into the first core can be removed by design changes for later cores, as operating experience is gained, and such considerations have been taken into account in this study. In the third case, design contingencies are not involved, since the evaluation is based on our present "best" determination of what values 
the nuclear data take, and it is assumed that all major improvements resulting from early operating experiences have been factored into the designs. Thus, in this case the economic concern is not with the penalties resulting from design contingencies, but rather with the present uncertainties in predicting reactor performance after all possible design contingencies have been removed.

The sensitivity of fast breeder reactor performance to data uncertainties has been indicated by studies reported on both thermal and fast reactors. Early fast reactor studies by Moorhead (1) and Greebler and Hutchins ${ }^{(2)}$ pointed out the large uncertainties which existed in fast reactor computations due to data uncertainties. Comparison of papers by Kinchin (3) and Smith ${ }^{(4)}$ in 1966 showed a factor of 3 to 5 difference in estimated accuracies of computcd reactivity for thermal and $f$ ast reactors, in part due to having more operating experience with thermal reactors. Papers presented in 1967 and 1968 by French ${ }^{(5,6)}$, Drake, et al (7), Craven and Perry ${ }^{(8)}$ and Greebler, et al $(9,10)$ indicated a fuel cost uncertainty for thermal and epi-thermal reactors of less than $0.05 \mathrm{mill} /$ $\mathrm{KW}(e) \mathrm{h}$ due to nuclear data uncertainties, compared to.fast reactor uncertainties in the range of 0.15 to $0.25 \mathrm{mill} / \mathrm{KW}(\mathrm{e}) \mathrm{h}$. Various aspects of the effects of data uncertainties on the physics of fast breeders have been investigated in recent years by küsters, et al (11), Broeders (12), Schmidl (13), Baile and Ravier (14), Candini, et al (15), and Kallfelz, et al (16). These studies provide further evidence that present uncertainties in nuclear data have an important effect on fast reactor analysis and design. Data uncertainties important in shielding design have been discussed recently by Penny (17).

Uncertainties in the data associated with the fissile and fertile fuel isotopes in a fast breeder reactor, $239 \mathrm{Pu}$ and $238 \mathrm{U}$, are of principal importance ${ }^{(2,4, \vdots 0)}$. Until recently, the ${ }^{239} \mathrm{Pu}$ alpha below $15 \mathrm{keV}$ was the most significant data uncertainty. The good agreement finally achieved between differential ${ }^{239} \mathrm{Pu}$ alpha values below $15 \mathrm{keV}$ measured in several laboratories worldwide $(18,19,20)$ has considerably improved confidence in the nuclear data used for fast reactor calculations. Yore recent integral measurements $(21,22)$ still indicate a higher ${ }^{239} \mathrm{Pu}$ alpha, but the total uncertainty has been reduced to a level similar to that of other important reactions. 
Although the most important data uncertainties remain those that relate directly to core and fuel performance, the uncertainties in the neutron removal cross section data most important to shielding calculations, especially steel isotopes and sodium, are becoming increasingly more significant as more detailed plant layouts are made for the several prototype or demonstration plants in the various national fast breeder programs. This significance has been accentuated in recent years by the recognition of the importance of the problem of neutron irradiation damage to structural materials $(23,24)$. Recent activity in the design of fabrication facilities and fuel shipping casks for fuel utilizing high-burnup plutonium has focused attention on the inadequacy of the cross section data pertaining to the production of the neutron-source isotopes that occur in highburnup plutonium.

Sections 2.0 and 3.0 below deal with the uncertainties in predicted physics core parameters and in shielding requirements due to combined data uncertainties and the significance of such prediction uncertainty to reactor design operation. Section 4.0 considers important specific data uncertainties and their individual effects on predicted core and fuel performance parameters. 


\subsection{UNCERTAINTIES IN PREDICTED CORE PARAMETERS}

Table I lists core compositions and geometries, and several physics parameters for two fast breeder reactors. One is for a $1000 \mathrm{MW}(e)$ reactor which is intended here to be reasonably representative of the expected high core and fuel performance of mature fast breeder systems: The parameters listed are for an equilibrium fuel cycle with a 50,000 MW $(t) d / t$ average core fuel burnup halfway through a one-year operating interval between refuelings. Plutonium atom percent isotopic ratios in the fresh fuel are $72 / 22 / 4 / 2$, for $239 / 240 / 241 / 242$, representative of plutontum recycled in a fast breeder system.

The second is for a $300 \mathrm{MW}(e)$ reactor intended here to be reasonably representative of a conservatively-designed first core in a prototype or demonstration breeder plant for near-term construction. The conservative design includes factors such as large pitch-to-diameter ratio for fuel pins to reduce coolant pressure drop, large allowances for irradiation swelling of the fuel element structural material (steel), axial expansion voids in the fuel pins to accomodate fuel swelling, stringent requirements for primary and secondary control shutdown mechanisms with tight limits on the maximum reactivity worth of any single mechanism, stringent requirements for a minimum Doppler coefficient, and limits on reactivities associated with sodium volding configurations. Conservatism of design in most of these areas tends to reduce the fuel volume fraction or to otherwise alter the core composition and geometry in such a manner as to reduce the fissile breeding ratio and increase the inventory of fissile material. The parameters listed in Table I are for a first core at $25,000 \mathrm{MW}(t)-\mathrm{d}-\mathrm{t}^{-1}$ average core fuel burnup halfway through a 6 -month operating interval between refuelings. Plutonium 1sotopic ratios in the fresh fuel are $59 / 26 / 12 / 3$, representative of plutonium discharged from a water reactor.

These two reactor models will be used as examples to illustrate the implications of data uncertainties to reactor design and operation. 
TABLE I. TYPICAL DESIGN PARAMETERS FOR EARLY 300 MW(e) AND MATURE 1000 MW(e) LIQUID METAL FAST BREEDER REACTOR CORES

Parameter

Core Height/Diam. (meter)

Fuel (vol.\% $\mathrm{PuO}_{2}-\mathrm{UO}_{2}$ )

Steel/Sodium/BeO/B 4 C (vol.\%)

Core Fuel Burnup (NW $(t)-d-t^{-1}$ )

Core Avg. Fuel. Linear Power (W/cm)

Core Peak-to-Avg. Power Density $(\mathrm{b})$

$239 \mathrm{Pu}+241 \mathrm{Pu}$ in Reactor $(\mathrm{Kg})$

Breeding Ratio

Doubling Time (year)

Doppler Effect - Sodium In ( $\mathrm{T} d \mathrm{k} / \mathrm{dT}$ )

Doppler Effect - Sodium Out ( $T \mathrm{dk} / \mathrm{dT}$ )

Total Sodium Void Reactivity (\$)

Single-Element Sodium Void Reac. (\$)

Total Shim Control Rod Reactivity (\$)

Fluence at Core Center (nvt $>1 \mathrm{MeV}$ )

In Spent Fuel Element (nvt Total)
$300 \mathrm{MW}(\mathrm{e})$

$.76 / 2.0^{(\mathrm{a})}$

33

$23 / 41 / 2 / 1$

50,000

230

1.6

1050

1.2

30

$-.0060$

$-.0040$

0

.04

15

$2.5 \times 10^{2.2}$

$2.5 \times 10^{23}$
1000 NW (e)

$.76 / 2.5^{(a)}$

47

$15 / 37 / 0 / 1$

100,000

315

1.6

2300

1.4

8

$-.0060$

$-.0037$

2.2

.06

7

$7 \times 10^{22}$

$7 \times 10^{23}$

(a). Assume $40 \mathrm{~cm}$ blanket thicknesses with volumetric composition similar to the core for alal blankets; 50 vol.\% fuel, 20 vol.\% steel, and 30 vol.\% sodium. for radial blanket; depleted $\mathrm{UO}_{2}$ for fresh blanket tuel.

(b). Includes radial power peaking for a two-zone core (higher Pu-to-U ratio In the outer zone), axial power peak1ng, and local power peaking due to control rod perturbations and variations in burnup between different fuel elements in the same region of the core. 


\subsection{Current Prediction Uncertainties and Progress for Improvement}

Table II indicates the current status of uncertainty in several important predicted physics parameters due to uncertainties in nuclear. data. The uncertainty ranges in Table II are estimated to represent crudely a $90 \%$ confidence level that the actual value of the predicted parameter falls within the indicated range. The uncertainty ranges are approximately the same for the two reactors listed in Table $I$, but the implications of these uncertainties to design can be appreciably different for the two reactors, as discussed in Section 2.2.

The effects of current data uncertainties are compared in Table II with those of data uncertainties that existed in 1966 for several of the listed parameters. The "1966" uncertainties were estimated from the data uncertainty ranges of references $(9,10)$. These are essentially the same as the data uncertainties used for the 1966 Washington Conference paper ${ }^{(2)}$, except the latter considered only data in the energy interval 0.1 to $100 \mathrm{keV}$. Goals for data improvement over a 5-year period, expressed in terms of uncertainties in calculated physics parameters, were also recommended at the 1966 Washington, D. C., conference over the neutron energies 0.1 to $100 \mathrm{keV}$. The "1966" uncertainties and the "1971" goals" in. Table II are corrected to take into account the data uncertainties in $\bar{v}$ and neutron energles above $100 \mathrm{keV}$. The additional corrections are based on the studies of sensitivity to data uncertainties reported in references $(9,10)$, from which it is deduced that about two-thirds of the uncertainty in currently ralculated physics parameters is associated with the neutron energy range $100 \mathrm{eV}$ to $100 \mathrm{keV}$.

Comparison of the current uncertainty ranges with those reported in the 1966 paper (2) shows that significant progress has been made in improvement of the data required for reactor core design. The most important data refinement was in the ${ }^{239} \mathrm{Pu}$ alpha below $15 \mathrm{kev}(18,1,9,20)$. Several independent measurements of $238_{U} \sigma(n, y)(25,26,27)$ somewhat reduced the large uncertainties in this data. Also, there were a number of in-depth evaluations of fuel isotopic data $(28,29,30,31)$ during this period which both reduced uncertalnties and helped to Identify diccrepancies between absolute measurements based on different standards. 
TABLE II. UNCERTAINTY RANGES IN PREDICTED PHYSICS PARAMETERS OF FAST BREEDER POWER REACTORS DUE TO NUCLEAR DATA UNCERTAINTIES.

Parameters

$239+241 \mathrm{Pu}$ Inventory in Reactor ( $\pm \%)$

Breeding Ratio ( \pm )

Doppler Coefficient $( \pm \%)$

Total Sodium Void Reactivity ( $\pm \$)$

Control Rod Reactivity Worth ( $\pm \%)$

Peak-to-Avg. Core Power Density ( $\pm \%)$

Total Neutron Flux at Reactor Vessel

${ }^{24} \mathrm{Na}$ Radiation Level in Secondary

Coolant Circuit

Neutron Source Level of Recycled Pu

Economic Factors

Doubling Time (years)

Fuel Cost $( \pm m i 11 / K W(e) h)$

\section{Uncertainty Range}

\begin{tabular}{lll}
\hline Present (a) $\quad 1966$ & Goals \\
\hline
\end{tabular}

$\begin{array}{lll}8 & 10 & 3 \\ .10 & .13 & .05 \\ 20 & 30 & 10 \\ 2.0 & 2.3 & 1.5 \\ 15 & & \end{array}$

5

$1 / 3$ to 3

$1 / 10$ to 10

$1 / 5$ to 5

5.8 to 11.5

0.13

(a) See Tables III, IV, and V for individual data contributions to uncertainties in predicted breeding ratio, fissile inventory, and fuel cost. 
The "1971 Goals" for data accuracy recommended as a 5-year program objective in the 1966 paper $^{(2)}$ appear unlikely to be met---see Table II-if one simply extrapolates from the 1966 and the current uncertainties. However, the accelerated pace of important nuclear data measurements along with concerted international efforts to identify the causes for data differences between measurements, offers encouragement that more rapid improvement is forthcoming. New measurement facilities, such as the Oak Ridge Laboratory's linac, ORELA, (32) can be expected to also play an important part in improving data accuracies.

Uncertainties due to inadequate computational models (e.g. 1imitations of computer codes) add to the uncertainties indicated in Table II due to inadequate data accuracy. It is estimated that the nuclear data uncertainties contribute most of the combined uncertainties due to methods and data in predicted fissile $\mathrm{Pu}$ inventory, breeding ratio, and neutron source level in recycled plutonium; more than half of the combined uncertainty in calculated Doppler coefficient, total sodium void reactivity, total control rod worth, and neutron flux and radiation level parameters related to plant shielding; and less than one-half of the combined uncertainty in power distribution. Thus, current data uncertainties contribute significantly to the uncertainties in predicted parameters that have a direct bearing on the economical and salecy performance of fast breeder reactors.

\subsection{Implications of Uncertainties in Predicted Core Physics Parameters}

For the mature large fast breeder plants, the domfnal Eunsideration Involving the uncertalnties in nuclear data is the ultimate effect that these uncertainties will have on the fuel cycle parameters, fissile inventory and breeding ratio. These parameters largely determine the fissile doubling times, which, in turn, effect not only the fuel cost of the breeder reactors, but also of thermal reactors that discharge plutonium which will be needed by new fast breeder reactors in a growing econuuiy (23). Current uncertainty in the doubling time potential of large fast breeder systems due to uncertain data contributes to the difficulty of predicting what the long-range balance w111 be between breeder and non-breeder 
reactors and the associated requirements for uranium, as well as the long-range fuel costs.

To illustrate the fuel cost influence of the data uncertainties, consider for the $1000 \mathrm{MW}(\mathrm{e})$ reactor of Table I the \pm 0.1 uncertainty in the breeding ratio and the $\pm 8 \%$ in the fissile plutonium inventory shown in Table II as $90 \%$ confid'ence limits. These uncertainties result in a doubling time uncertainty range from 5.8 to 11.5 years and a $\pm 0.13 \mathrm{mill} / \mathrm{KW}(\mathrm{e}) \mathrm{h}$ uncertainty in the fuel cost also shown in Table II. These estimated doubling time and cost uncertainties assume a $30 \%$ outof-pile fissile $\mathrm{Pu}$ inventory, a US $\$ 10 / \mathrm{gm}$ fissile $\mathrm{Pu}$ value, a $10 \% / \mathrm{yr}$ interest rate on fuel, and an $80 \%$ plant load factor. The $0.13 \mathrm{mill} / \mathrm{kW}(\mathrm{e}) \mathrm{h}$ fuel cost differential represents an uncertainty of about US $\$ 900,000$ per year in operating cost for a single $1000 \mathrm{MW}(\mathrm{e})$ plant. The uncertainty range in doubling time translates into a difference of about one million tons in cumulative $\mathrm{U}_{3} \mathrm{O}_{8}$ ore requirements over a 35 -year period between 1985 and 2020 using one projective buildup of fast breeder electrical generating capacity $(34)$.

The implications of nuclear data uncertainties to the design and operation of the near-term prototype or demonstration plants are more complex than for the case of the mature fast breeder plant discussed above. Because of their developmental status, the near-term breeder plants will have high capital and fuel processing costs. Hence, the differentials in the fuel cost associated with the data uncertainties will not have much impact toward making these plants economically competitive. Emphasis will be placed on assurance of reliability and safety, with many of the component and material operating limits not known nearly as well as they will be for the later mature breeder plants which. w111 have the benefit of the earlier operating experience and of considerable additional information from continuing national breeder development programs. Performance goals will generally be modest, espectally for a first core, compared with those for the mature large breeder plants, to provide allowances for present uncertainties in thermal-hydraulic and mechanical characteristics. Factors influencing these allowances are irradiation-induced swelling of steel, thermal conductivity of fuel, 
material temperature limits, hydraulic pressure differentials, and behavior of coolant and fuel under transiont conditions of varying severity for safety considerations, as well as the direct uncertainties. in the predicted physics parameters. There will, nevertheless, be some Important performance goals and these will no doubt include a modest demonstration of breeding capability and of high fuel power density.

The core parameters of the illustrative $300 \mathrm{MW}(\mathrm{e})$ reactor of Table I show such a compromise in performance goals to allow for the current status of technological uncertainties. The relatively low fuel volume fraction, compared with that of the mature $1000 \mathrm{MW}(\mathrm{e})$ design, results mainly from the design changes made to allow for the uncertainties; and. it appreclably reduces the breeding ratio and increases the fissile inventory. Uncertainties in the predicted amount of control required for burnup and for temperature changes between shutdown and full power operation, combined with uncertainties in predicted control rod strengths. and a stringent limit imposed on the strength of a single control rod, significantly adds to the number of control rods required. This is one of the factors that contributes to the decrease in fuel. volume fraction and, hence, in breeding ratio. In order to assure an adequate Doppler coefficient under the conditions of a voided core; and fully-inserted shim control at the beginning of operation after a refueling, and taking Into account also the uncertainty in the predicted Doppler coefficient, a small amount of moderating material, $\mathrm{BeO}$, is included in the core composition of the $300 \mathrm{MW}(\mathrm{e})$ reactor of Table I. An adequate Doppler coefficicnt muct sufficient 1y limit energy release in a maximum hypothetical accident to assure integrity of the containment. The addition of $\mathrm{Be} 0$ further decreases the breeding rat1o. The predicted breeding ratio of 1.2 shown in Table I for the $300 \mathrm{MW}(e)$ reactor provides a reasonable assurance of at least a 1.1 breeding ratio, and the possibility of one as high as 1.3 based on the uncertainty range indicated in Table II.

The lower fuel linear power in the first core of the $300 \mathrm{MW}(e)$. reactor, relative to the mature $1000 \mathrm{MW}(\mathrm{e})$ reactor, increases the fissile inventory and results from allowances for the uncertainties in the thermal properties of the fuel as well as the uncertaintice in the predicted power distributions. It should be noted that critical assembly mockup 
experiments conducted in support of the design would reduce several of the uncertainties in the predicted parameters well below the ranges Indicated in Table II, especially for fissile inventory and control rod worths. Running such a critical experimental program is in itself a significant cost factor, and if it includes only a final proof-test mockup, many of'the core design contingencles will have already been finalized. 


\subsection{UNCERTAINTIES IN PREDICTED SHIELDING REQUIREMENTS AND RADIATION SOURCES}

\subsection{Plant Shielding}

Table II also lists uncertainty ranges in radiation levels important to shield design. These ranges are based on a $\pm 20 \%$ uncertainty in removal cross sections. The factor of about a one-half decade uncertainty in the flux level at the reactor vessel is an example of the design allowances that must be made to adequately shield structural components In and near the reactor vessel against excessive irradiation-damage fluences. The extra thickness of the radial shield inside the vessel to accommodate the uncertainty is $12 \mathrm{~cm}$, producing roughly. an equal increase in the vessel radius. The approximately one-decade uncertainty in the activation of sodium in the secondary coolant circuit requires an additional $4 \mathrm{~cm}$ of $\mathrm{B}_{4} \mathrm{C}$ shielding around the intermediate heat exchangers for a design in which the components of the primary coolant circuit are immersed in a sodium pool. Similar extra shielding allowances required throughout a $300 \mathrm{MW}(\mathrm{e})$ : size plant represents an increase in the capital cost of such a plant estimated to be in the order of one million dollars. The uncertainties indicated in the shielding area examples listed in Table II may be high estimates in light of better agreement obtained between some calculations and benchmark experiments ${ }^{(35)}$. However, such experiments tend to have considerably simpler geometrical configurations and composition arrangements than those involved in a fast breeder plant, especialiy for the deep penetration paths. The uncertainties in shielding predictions indicated in Table II due to uncertainties in the nuclear data are very rough estimates since there has not been a systematic evaluation of all the shielding data uncertainties important to fast breeder systems, accompanied by a quantitative assessment of the effects of the combined uncertainties on predicted radiation levels at sensitive locations throughout such a plant.

Shielding data requirements for reactor design and operation include several important types ${ }^{(17)}$. Total cross sections and the angular distribution of elastic scattering cross sections are required in the $\mathrm{keV}$ and $\mathrm{MeV}$ energy range for deep penetration calculations. In addicion, the level excitation for inelastic scattering is required to be able to predict 
neutron spectra accurately. Gamma rays produced by neutron capture and following inelastic scattering are also needed for shielding calculations. Differences between thermal neutron capture spectra and the resonance spectra have been found to be significant and indicate that the capturegamma ray spectra should be known for all incident neutron energies.

\subsection{Neutron Source Uncertainties in Fue1 Processing}

The factor of five uncertainty in the neutron source level of recycled plutonfum--see Table II--contributes to the uncertainty in specifying shielding requirements for fuel fabrication and for shipment of spent fuel. Fabrication costs are sensitive to the requirements for neutron shielding to the extent that such requirements influence the complexity of mechanization necessary for the various fabrication handing operations. Uncertainties in the nuclear data involved in the reactions leading to the buildup of ${ }^{236} \mathrm{Pu}$ and ${ }^{238} \mathrm{Pu}$ are the most important ones for improving the accuracy of the neutron source data used for shield design of fabrication plants (36). Uncertainties in the nuclear data involved In the reactions leading to the buildup of ${ }^{242} \mathrm{Cm}$ and ${ }^{244} \mathrm{Cm}$ are the most important ones for improving the accuracy of neutron source data used for shielding design of spent fuel shipping casks (37). (The latter is a problem not only for plutonium-fueled fast breeder systems, but also for uranium-fueled thermal reactors that discharge plutonium in fuel elements irradiated to high burnup.)

The principal reactions leading to the formation of $236 \mathrm{Pu}, 238 \mathrm{Pu}$, ${ }^{242} \mathrm{Cm}$, and ${ }^{244} \mathrm{Cm}$ are shown in Figure 1 . Snyder ${ }^{(38)}$ evaluated the requirements for data accuracy and indicated the status of the data uncertainties for thermal reactor systems. In plutonium-fueled, breeder reactors the buildup of ${ }^{236} \mathrm{Pu}$ and ${ }^{238} \mathrm{Pu}$ is almost entirely due to the sequence starting with the $(n, 2 n)$ reaction in ${ }^{238} \mathrm{U}$. The buildup of ${ }^{242} \mathrm{Cm}$ and ${ }^{244} \mathrm{Cm}$ follows from the irradiation and decay of the heavier plutonium isotopes and is, therefore, sensitive to the isotopic concentration of the fuel source. (There is a considerably higher content of ${ }^{241} \mathrm{Pu}$ and ${ }^{242} \mathrm{Pu}$ in plutonium discharged from a water reactor relative to that discharged from a fast reactor.) 


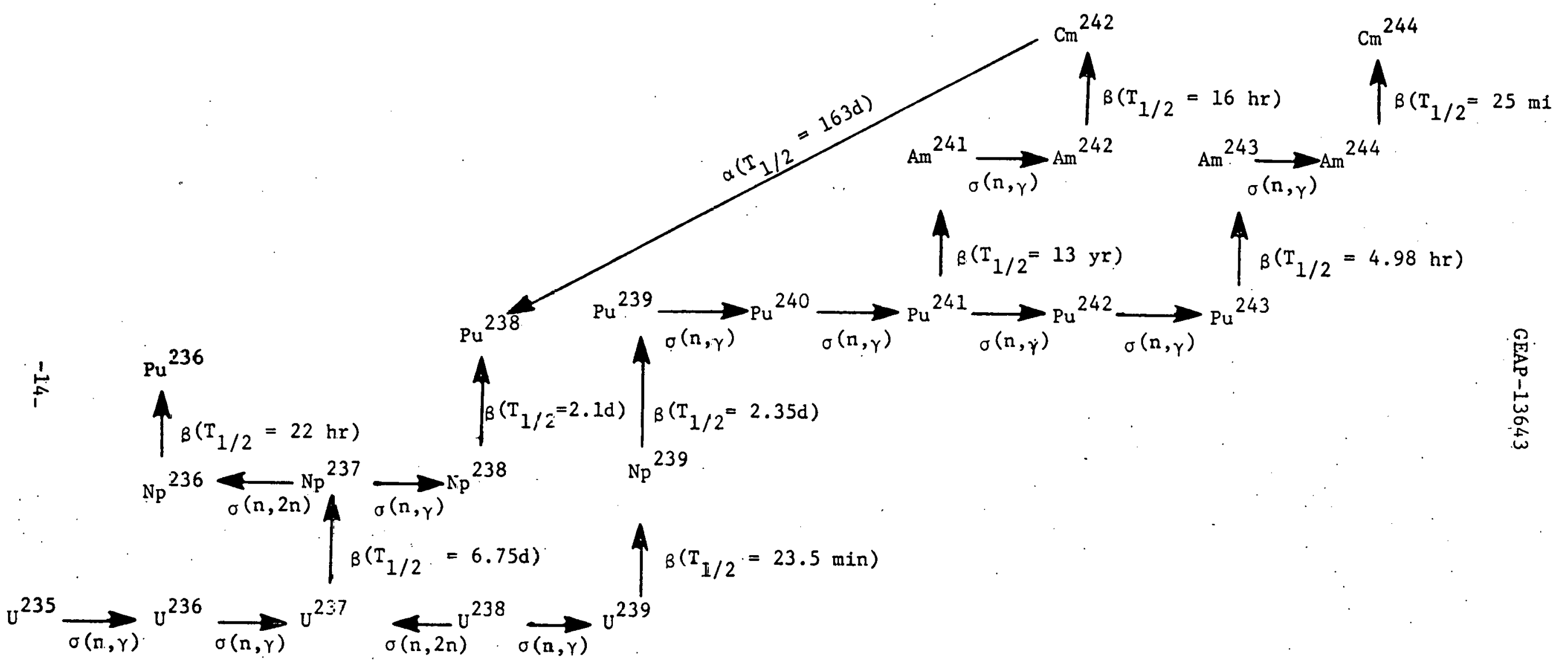

FIGURE 1. NOCLEAR REACTION SEQUENCES IN PU-U FUEL FOR FORMATION OF NEUTRON SOURCE ISOTOPES 
The most crucial data uncertainties in the above reaction chains are the $(n, 2 n)$ reaction for ${ }^{238} \mathrm{U}$, and the reactions shown in Figure 1 for ${ }^{237} \mathrm{~Np},{ }^{241} \mathrm{Am}$, and ${ }^{243} \mathrm{Am}$. Most of the data that is required for the determination of the neutron source isotopic concentrations are based upon nuclear model studies, integral measurements, and very few differential measurements at low energies.

Therefore, the present data uncertainties are very large and the estimated uncertainty in the neutron source level is about a factor of 5 . 


\subsection{EFFECTS OF SPECIFIC DATA UNCERTAINTIES}

\subsection{Present Uncertainties and Recommended 5-Year Accuracy Goals - Economic Implications}

Table III lists the effects of current data uncertainties in $23.9 \mathrm{Pu}$ and ${ }^{238} \mathrm{U}$ on the predicted breeding ratio and fissile inventory of the 1000 MW(e) reactor of Table I. Similar effects of data uncertainties in the higher plutonium isotopes, fission products, sodium, and steel are listed In Table IV. The significance of these uncertainties in the parameters of an advanced $1000 \mathrm{MW}(e)$ reactor is in the accuracy of presently evaluated economics of these reactors. Uncertainty ranges for the $300 \mathrm{MW}(e)$ reactor would be roughly the same as those ilsted in Tables III and IV for the $1000 \mathrm{MW}(\mathrm{e})$ reactor, but the significance is quite different, in that contingencies would be incorporated into the design to account for the uncertainties.

Tables III and IV also indicate the estimater magnitude of each of. the data uncertainties corresponding to a $90 \%$ confidence 1imit, while Table $\mathrm{V}$ shows a recommended goal for accuracy of the data in each case. Such accuracy will permit precise evaluations of reactor economy, and need to bc achieved before 1975, when it is expected that there will be considerable design activity on behalf of actual large breeder plants ( $1000 \mathrm{MW}(e))$ to be constructed for operation sometime in the 1980 decade.

Fuel cost uncertainty is much more sensitive to the uncertainties in breeding ratio than to those in fissile $\mathrm{Pu}$ inventory. A rough estimate of $0.01 \mathrm{mill} / \mathrm{KW}(\mathrm{e}) \mathrm{h}$ change in fuel cost for each 0.01 change in breeding ratio is appropriate for the fuel cost assumptions made in this study. A fuel cost change of $-.004 \mathrm{mill} / \mathrm{KW}(\mathrm{e}) \mathrm{h}$ for each $1 \%$ change in. fissile $\mathrm{Pu}$ inventory is a similar rough estimate for the same cost assumptions. This is based upon changes in doubling time for the $1000 \mathrm{MW}(\mathrm{e})$ reactor being given approximately by

$$
\delta(\text { years })=8.5[0.01 \delta \text { (fissile inventory) }-2.5 \delta \text { (breeding ratio) }]
$$

for small changes.

It is seen that the ${ }^{238} \mathrm{U} \sigma(n, \gamma)$ uncertainty below $100 \mathrm{keV}$ has the largest single effect on breeding ratio uncertainty. The fissile Pu 
TABLE III. EFFECTS OF 238 U AND 239 PU UNCERTAINTIES ON PREDICTED VALUES OF BREEDING RATIO AND FISSILE PU INVENTORY

\begin{tabular}{|c|c|c|c|c|}
\hline $\begin{array}{c}\text { Data } \\
\text { Uncertainty } \\
\end{array}$ & $\begin{array}{c}\text { Incident } \\
\text { Neutron Energy. }\end{array}$ & $\begin{array}{l}\text { Uncertainty } \\
\text { Range }( \pm \%)\end{array}$ & $\begin{array}{l}\text { Breeding } \\
\text { Ratio ( } \pm)\end{array}$ & $\begin{array}{l}\text { Fissile } \mathrm{Pu} \\
\text { Inventory }( \pm \%)\end{array}$ \\
\hline \multirow[t]{2}{*}{${ }^{238} U \sigma(n, \gamma)$} & 1 to $100 \mathrm{keV}$ & $10^{\circ}$ & .060 & 2.5 \\
\hline & $>100 \mathrm{keV}$ & 10 & .015 & 0.6 \\
\hline \multirow{2}{*}{${ }^{238} U \sigma\left(n, n^{\prime}\right)$} & .1 to $1 \mathrm{MeV}$ & 15 & .005 & 0.3 \\
\hline & $>1 \mathrm{MeV}$ & 20 & $: 015$ & 1.0 \\
\hline${ }^{238} U \sigma(n, f)$ & $>1 \mathrm{MeV}$ & 6 & .010 & 0.7 \\
\hline${ }^{238} \mathrm{U} \quad \bar{v}$ & $>1 \mathrm{MeV}$ & 3 & .005 & 0.5 \\
\hline \multirow[t]{3}{*}{${ }^{239} \mathrm{Pu} \sigma(\mathrm{n}, \mathrm{f})$} & .1 to $20 \mathrm{keV}$ & 10 & .003 & 1.5 \\
\hline & 20 to $300 \mathrm{keV}$ & 10 & .015 & 5.5 \\
\hline & $>300 \cdot \mathrm{keV}$ & 6 & .004 & 1.5 \\
\hline \multirow[t]{3}{*}{$23{ }^{9} \mathrm{Pu} \sigma(\mathrm{n}, \gamma)$} & .2 to $20 \mathrm{keV}$ & 20 & .020 & 1.0 \\
\hline & 20 to $80 \mathrm{keV}$ & 20 & .015 & 0.8 \\
\hline & $>80 \mathrm{keV}$ & 20 & .002 & 0.1 \\
\hline${ }^{239} \mathrm{Pu} \bar{v}$ & $>0.1 \mathrm{keV}$ & 2 & .040 & 3.0 \\
\hline${ }^{239} \mathrm{Pu} \quad \overline{\mathrm{E}_{X}(E)}$ & $>0.1 \mathrm{keV}$ & 10 & .025 & 2.0 \\
\hline $23{ }^{9} \mathrm{Pu} \sigma\left(\mathrm{n}, \mathrm{n}^{\prime}\right)$ & $>10 \mathrm{keV}$ & 40 & .005 & 0.3 \\
\hline
\end{tabular}

(a). The uncertainty range listed as a single value for the indicated energy range is intended to represent an effective average for roughly $90 \%$ confidence limits, taking into consideration the energy dependence of the reaction rates of interest and of the uncertainty in measured data within each indicated energy range. 
TABLE IV. EFFECTS OF UNCERTAINTIES IN FISSION AND RADIATIVE CAPTURE CROSS SECTIONS OF HIGHER PU ISOTOPES, FISSION PRODUCTS, SODIUM AND STEEL ON PREDICTED VALUES OF BREEDING RATIO AND FISSILE PU INVENTORY

\begin{tabular}{|c|c|c|c|c|}
\hline $\begin{array}{c}\text { Data } \\
\text { Uncertainty }\end{array}$ & $\begin{array}{c}\text { Incident } \\
\text { Neutron Energy }\end{array}$ & $\begin{array}{l}\text { Uncertainty }(a) \\
\text { Range }( \pm \%)\end{array}$ & $\begin{array}{l}\text { Breeding } \\
\text { Ratio ( } \pm \text { ) }\end{array}$ & $\begin{array}{l}\text { Fissile } \mathrm{Pu} \\
\text { Inventory ( } \%)\end{array}$ \\
\hline \multirow[t]{2}{*}{${ }^{240} \mathrm{Pu} \sigma(\mathrm{n}, \gamma)$} & 0.1 to $100 \mathrm{keV}$ & 30 & .005 & 0.3 \\
\hline & $>100 \mathrm{keV}$ & 40 & .001 & 0.1 \\
\hline \multirow[t]{2}{*}{${ }^{240} \mathrm{Pu} \sigma(\mathrm{n}, \mathrm{f})$} & 1 to $300 \mathrm{keV}$ & 30 & .003 & 0.2 \\
\hline & $>300 \mathrm{keV}$ & 15 & .003 & 0.2 \\
\hline${ }^{241} \mathrm{Pu} \sigma(\mathrm{n}, \mathrm{f})$ & $>0.1 \mathrm{keV}$ & 25 & .003 & 1.0 \\
\hline${ }^{241} \mathrm{Pu} \sigma(\mathrm{n}, \gamma)$ & $>0.1 \mathrm{keV}$ & 40 & .002 & 0.1 \\
\hline $\begin{array}{l}\text { Fission Produc } \\
\sigma(n, \gamma)\end{array}$ & $>0.1 \mathrm{keV}$ & 40 & .030 & 2.0 \\
\hline \multirow[t]{2}{*}{ Sodium $\sigma(n, \gamma)$} & 0.1 to $10 \mathrm{keV}$ & 30 & .003 & 0.2 \\
\hline & $>10 \mathrm{keV}$ & 50 & .001 & حo \\
\hline \multirow[t]{2}{*}{ Steel $\sigma(n, \gamma)$} & $<0.1 \mathrm{MeV}$ & 25 & .025 & 1.0 \\
\hline & $>0.1 \mathrm{MeV}$ & 35 & .010 & 0.5 \\
\hline Steel $\sigma\left(n, n^{\prime}\right)$ & $>0.8 \mathrm{MeV}$ & 15 & .005 & 0.3 \\
\hline
\end{tabular}

(a). See footnote (a) of Table III. 
TABLE V. CURRENT DATA UNCERTAINTIES AND RECOMMENDED ACCURACY GOALS FOR 1975

Data Type and Incident Neutron Energy Range

${ }^{238} \mathrm{U} \sigma(n, \gamma) 100 \mathrm{eV}$ to $1 \mathrm{MeV}$

${ }^{238} \mathrm{U} \sigma(\mathrm{n}, \mathrm{f}) 1$ to $10 \mathrm{MeV}$

${ }^{238} \mathrm{U} \sigma\left(n, n^{\prime}\right) 100 \mathrm{keV}$ to $10 \mathrm{MeV}$

${ }^{23}{ }^{9} \mathrm{Pu} \sigma(\mathrm{n}, \gamma) 0.1$ to $500 \mathrm{keV}$

$23{ }^{9} \mathrm{Pu} \sigma(\mathrm{n}, \mathrm{f}) 0.1 \mathrm{keV}$ to $10 \mathrm{MeV}$

$2{ }^{9} \mathrm{Pu} \bar{v} \quad>0.1 \mathrm{keV}$

${ }^{239} \mathrm{Pu} \overline{\mathrm{E}_{X}(\mathrm{E})}>0.1 \mathrm{keV}$

$240 \mathrm{Pu} \sigma(\mathrm{n}, \mathrm{f})>1 \mathrm{keV}$

$240 \mathrm{Pu} \sigma(\mathrm{n}, \gamma) 0.1 \mathrm{keV}$ to $1 \mathrm{MeV}$

${ }^{24} \mathrm{I} \mathrm{Pu} \sigma(\mathrm{n}, \mathrm{f}) \quad>0.1 \mathrm{keV}$

Fiss. Prod. $\sigma(n, \gamma)>0.1 \mathrm{keV}$

$\mathrm{Fe}, \mathrm{N1}, \mathrm{Cr} \sigma(\mathrm{n}, \gamma)>0.1 \mathrm{keV}$

Combined Data Uncertainties

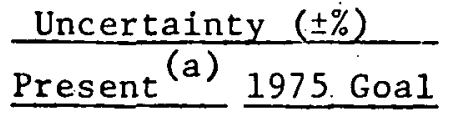

10

6

20

20

10

2

10

20

30

25

40

30

5

2

10

10

10

10

Cost Uncertainty

for $1000 \mathrm{NW}(\mathrm{e})$ Reactor (Imi11/KW(e)h)

Present 1975 Goal

.065

.013

.013

.006

.025

.008

.025

.045

.007

.034

.007

.050

.013

.033

.006

.008

.004

.004

.001

.007

.003

.038

.010

$\frac{.041}{0.13}$

$\frac{.010}{0.03}$

(a) Corresponds to values 11sted in Tables III and IV for estimated $90 \%$ confidence limits. 
inventory is most affected by the uncertainty in ${ }^{239} \mathrm{Pu} \sigma(\mathrm{n}, \mathrm{f})$ between 20 and $300 \mathrm{keV}$. The uncertainties in ${ }^{239} \mathrm{Pu}$ alpha, $\bar{v}$, and average energy of fission spectrum neutrons $\overline{E_{X}(E)}$, in $238 U \cdot \sigma\left(n, n^{\prime}\right)$ and $\sigma(n, f)$, in ${ }^{240} \mathrm{Pu} \sigma(n, \gamma)$ and $\sigma(n, f)$, in ${ }^{241} \mathrm{Pu} \sigma(n, f)$, and in $\sigma(n, \gamma)$ of steel and of fission products also have significant effects on the accuracy of predicted physics parameters for a fast breeder reactor. Uncertainties in the $\sigma(n, \gamma)$ of ${ }^{238} \mathrm{U}$, and of other fertile isotopes such as ${ }^{240} \mathrm{Pu}$, have opposite fuel cost effects on breeding ratio and fissile inventory. For example, a higher ${ }^{238} \mathrm{U} \sigma(\mathrm{n}, \gamma)$ increases both the breeding ratio and the fissile inventory. However, the effect on the breeding ratio is the dominant one for both fuel cost and fissile doubling time. For all the other data uncertainties listed in Tables III and IV, the corresponding uncertainties in the breeding ratio and the fissile inventory occur In a consistent direction insofar as their effects on fuel cost and doubling time are concerned.

Table $\mathrm{V}$ indicates the present data uncertainty ranges for estimated $90 \%$ confidence limits and recommended targets for Improvement of data accuracy in the next five years. Fuel cost uncertainties for the advanced $1000 \mathrm{MW}(\mathrm{e})$ reactor, which are assoctated with the present and the target data uncertainties, are also listed in the table. The target data accuracy gives a combined fuel cost uncertainty of $0.03 \mathrm{mill} / \mathrm{KW}(\mathrm{e}) \mathrm{h}$, compared with the present estimated uncertainty of $0.13 \mathrm{mill} / \mathrm{KW}(\mathrm{e}) \mathrm{h}$ due to combined nuclear data uncertainties. These combined fuel cost uncertainties are based on the assumption that each of the listed data uncertainties are correlated over the entire energy range indicated, but there is no correlation between ranges. This assumption is too pessimistic and tends to compensate for the estimated $90 \%$ confidence limits, which are probably too optimistic.

For target accuracies of each of the major data uncertainties, a fuel cost uncertainty of about $0.01 \mathrm{mill} / \mathrm{KW}(\mathrm{e}) \mathrm{h}$ was chosen to arrive at the combined $0.03 \mathrm{mill} / \mathrm{KW}(\mathrm{e}) \mathrm{h}$. It is seen that high precision, $3 \%$ or less uncertainty for $90 \%$ confidence limits, is required for fission and capture cross sections of $238 \mathrm{U}$ and ${ }^{239} \mathrm{Pu}$, as well as for the fission spectrum of $239 \mathrm{Pu}$. The $\bar{v}$ uncertainty for ${ }^{239} \mathrm{Pu}$ needs to be known very precisely, to the order of $0.5 \%$ in the energy range above $0.1 \mathrm{keV}$. On 
the other hand, uncertainties of the order of $10 \%$ (for $90 \%$ confidence limits) are acceptable for the data of other fuel isotopes and core structural materials for total cost uncertainty of $0.03 \mathrm{mill} / \mathrm{KW}(\mathrm{e}) \mathrm{h}$. It is apparent that to achieve such a target accuracy. in the next five years, intensive effort will have to be focused on improving the precision of the important ${ }^{238} \mathrm{U}$ and ${ }^{239} \mathrm{Pu}$ data.

\subsection{Sources for Estimation of Specific Data Uncertainties}

Data uncertainty ranges which were determined for a paper presented at the 1968 Conference on Neutron Cross Section Technology (10) were used as the bases for the present estimated uncertainties. Data measurements and evaluations made since 1967 and described below have been used to modify those ranges where appropriate.

The more important measurements made since 1966 which have resulted in the reduction of data uncertainties are for ${ }^{239} \mathrm{Pu}$ and ${ }^{238} \mathrm{U}$. In addition, detailed evaluations have been made which also tend to reduce the data uncertainties for these fuel isotopes by a) comparing measurement techniques, b) showing consistency with theory, and c) reducing measured results to common normalizations. These evaluations have served the further purpose of identifying points of departure among the various measurements of the same quantities.

The $239 \mathrm{Pu}$ alpha value below $20 \mathrm{keV}$ ranks as the nuclear quantity which has shown greatest improvement in accuracy since 1966. The final measurements of Gwin, et al, (18), made at RPI, and Czirr and Linesey (19) show good agreement in both magnitude and energy variation. Recent results from the U.K. ${ }^{(20)}$ are slightly lower, while those of Sukhorouchkin run a little higher. An analysis of single level statistical resonance parameters made by Evatt and Hutchins ${ }^{(40)}$ indicate that a single set of parameters produce good agreement between the computed values and measured data for both the alpha value and the fission cross section up to $25 \mathrm{keV}$. Two recent integral measurements $(21,22)$, however, suggest a higher value. Therefore, the uncertainty range for $\sigma(n, \gamma)$ was taken to be $\pm 20 \%$, the same as used above $20 \mathrm{keV}$.

A large number of fission cross section measurements of $239^{\mathrm{Pu}}$ have been reported in the last few years. Included are those of James and Patrick ${ }^{(29)}$, Shunk, et al ${ }^{(41)}$, Gwin, et al ${ }^{(18)}$, Gilboy and Knoll (42), 
Ryabov, et a1 ${ }^{(43)}$, White and Warner ${ }^{(44)}$ and Lehto ${ }^{(45)}$. In spite of the number of reported measurements, many of which are over the same energy ranges, the uncertainty in $\sigma(\mathrm{n}, \mathrm{f})$ for ${ }^{239} \mathrm{Pu}$ has not significantly.decreased. Since the basic measurement in a majority of the reported results is the ratio ${ }^{239} \mathrm{Pu} \sigma(n, f) / 235_{U} \sigma(n, f)$, Davey ${ }^{(28)}$, Hart ${ }^{(30)}$, and Greene, et al ${ }^{(46)}$ have used this ratio in attempts to arrive at consistent normalizations. The effects on reactor calculations resulting from this approach are still not understood and no significant consideration was given to it in arriving at the $\sigma(n, f)$ uncertainties.

A considerable amount of attention has also been given to the measurements of ${ }^{238} \mathrm{U} \sigma(\mathrm{n}, \gamma)$, particularly between 1 and $500 \mathrm{keV}$. The data of Moxon ${ }^{(25)}$ are considerably lower than the earlier values reported by Macklin, et al (47), while independent absolute measurements by Menlove and Poenitz (26) fall between. Petral bomb results at lower energies, reported by Glass, et al ${ }^{(27)}$, produced an average resonance radlation width which is some 20 percent lower than previous values, also indicating lower values of $\sigma(n, \gamma)$ at high energies. Two recent measurements made in the Soviet Union are in disagreement. Values of Panttkin ${ }^{(48)}$ are in good agreement with Menlove and Pönitz from 25 to $150 \mathrm{keV}$, while an absolute measurement by Stavisskii (49) shows agreement with the lower Moxon data, although these results are still preliminary. Measurements made at GGA by Fricke ${ }^{(50)}$ from $1 \mathrm{keV}$ to $1 \mathrm{MeV}$ agree with Moxon below $10 \mathrm{keV}$ and with the higher pönitz values above $10 \mathrm{keV}$. Davey ${ }^{(31)}$ has made an in-depth review of the $238 \mathrm{U} \sigma(n, \gamma)$ situation and points out the basic disagreement which exists between "absolute" measurements. These measurements and evaluations have resulted in a smaller uncertainty in ${ }^{238} \mathrm{U} \sigma(\mathrm{n}, \gamma)$ than in 1966. However, the basic disagreement in absolute measurements exists and must be resolved before further significant improvement can be expected.

Recent preliminary results by A. B. Smith ${ }^{(51)}$ for $238 U \sigma\left(n, n^{\prime}\right)$ Indicate a harder secondary neutron spectrum than obtained by Barnard, et $a_{1}^{(52)}$, which seems to be in closer agreement with integral measurements. However, it was not felt that there is a significant reduction 
In the uncertainty in this cross section, and the ranges for ${ }^{238} \mathrm{U}$, as well as $23{ }^{9} \mathrm{Pu}$ and stainless steel, are essentially the same as in 1966. The potential of the optical model in predicting inelastic cross sections gives some hope to reducing these uncertainties in the next years.

The uncertainties in the fission cross sections of $238 \mathrm{U}$ and $24^{\circ} \mathrm{Pu}$ are nearly the same as in 1966. Measurements have been reported by Stein, et al ${ }^{(53)}$, White and Warner ${ }^{(44)}$, and Byers, et al ${ }^{(54)}$; but the threshold nature of these cross sections makes them remain uncertain. The ${ }^{240} \mathrm{Pu} \sigma(\mathrm{n}, \gamma)$ uncertainty range was also not reduced, in spite of resolved resonance parameters isolated at GEEL, due to the various values reported for $\Gamma_{\gamma}$ and lack of direct capture data above $10 \mathrm{keV}$. While resolved resonance parameters have been determined at low energies for ${ }^{24 l} \mathrm{Pu}$, they have not been instrumental in reducing the cross section uncertainties at higher energies. In fact the ${ }^{241} \mathrm{Pu} \sigma(\mathrm{n}, \gamma)$ uncertainty was increased over that in 1966 to be more representative of the lack of data for this cross section.

The stainless steel $\sigma(n, \gamma)$ uncertainty was decreased principaily due to high resolution measurements of the total and scattering cross sections by Barnard, et al ${ }^{(55)}$, Cierjacks, et al (56), and Carlson, et al $^{(57)}$.

The uncertainty ranges for the remaining materials and cross sections are about those of 1966, with the exception of $\mathrm{Na} \sigma(n, \gamma)$ below $10 \mathrm{keV}$, due to better substantiation of the value of $\Gamma_{\gamma}$ for the 0.29 $\mathrm{keV}$ resonance. The uncertainty in $\bar{v}$ values remains relatively large. While the thermal values are more definite, the energy dependence of $\bar{v}$ up to $500 \mathrm{keV}$ is in question as a result of measurements of Meadows (58) and Kuznetsov ${ }^{(59)}$ for $235 \mathrm{U}$. More recently, energy dependent measurements of $\bar{v}$ for ${ }^{239}$ Pu have been reported by Savin ${ }^{(60)}$, Vorsheva ${ }^{(61)}$, Kuznetsov ${ }^{(62)}$, and Soleilhac ${ }^{(63)}$. However, data between 100 and 500 $\mathrm{keV}$ is still sparse and resolution is not posstble. The uncertainties in the fission neutron spectra have increased somewhat due to foil measurements by Grund ${ }^{(64)}$ and McElroy ${ }^{(65)}$ which indicate a harder spectrum for $235 \mathrm{U}$. 
Arriving at uncertainty limits for individual nuclear quantities is only part of the analysis which relates data to the uncertainties in fast reactor parameters. The degree of correlation between the data errors is important and not at all certain. Procedures of evaluation as used by Davey ${ }^{(28)}$, which arrive at common normalizations, tend to increase the correlation of errors. The propagation of errors in this study is based upon the condition that the data errors are only correlated for a single quantity over the energy ranges indicated in Tables III and IV. Also, the effects that resonance parameters, as such, have on the reactor parameters have not been studied, although it is believed that this effect is of lesser importance.

Finally, the values chosen for the 1975 measurement goals given in Tabie $\mathrm{V}$ may appear to be too optimistic. There are two reasons why these goals may be realizable in the next 5 years and an optimistic attitude can be fustified. First, the measurement programs at many facilities are focusing more directly on the needs of the reactor industry, and the scientists involved are applying their expertise in the evaluation of data. Second, basic differences between "absolute" measurements are being identified (31). This provides the real possibility that a number of measurement differences will be understood and eliminated in the next 5 years. Elimination of these differences in absolute measurements is the main key to achievement of the tight measurement goals listed in Table $\mathrm{V}$. 


\section{REFERENCES}

1. MOORHEAD, T.P., "The Effects of Errors in Cross Section Data on Calculations for a Large Dilute Fast Reactor", Conference on Physics of Fast and Intermediate Reactors, II, IAEA, Vienna (1962).

2. GREEBLER, P., HUTCHINS, B.A., "User Requirements for Cross Sections in the Energy Range from $100 \mathrm{eV}$ to $100 \mathrm{keV}$ ", Conference on Neutron Cross Section Technology, Washington, D. C., March 22-24 (1966).

3. KINCHIN, G.H., "Nuclear Data Requirements for Thermal Reactor Design and Operation", Conference on Nuclear Data for Reactors, Paris, October 17-21 (1966).

4. SMITH, R.D., "Nuclear Data Requirements for Fast Reactor Design and Operation", Conference on Nuclear Data for Reactors, Paris, October 17-21 (1966).

5. FRENCH, R.J., "Use of Neutron Data in Thermal Reactor Power Plant Design", 1967 Winter Meeting of American Nuclear Society, Chicago, November 5-9 (1967).

6. FRENCH, R.J., "Use of Neutron Data in Thermal Reactor Power Plant Design", Conference on Neutron Cross Section Technology, Washington, D. C., March 4-7 (1968).

7. DRAKE, M.K., STEWART, H.B., TAYLOR, R.C., "The Effects of Cross Section Uncertainties in the HTGR", 1967 Winter Meeting of American Nuclear Society, Chicago, November 5-9 (1967).

8. CRAVEN, C.W., Jr., PERRY, A.M.," Sensitivity of Molten-Salt Breeder Reactor Economics to Uncertainties in Basic Nuclear Data", 1967 Winter Meeting of American Nuclear Soclety, Chicago, November 5-9 (1967).

9. GREEBLER, P., "Sensitivity of Fast Reactor Economics to Uncertainties in Nuclear Data", 1967 Winter Meeting of American Nuclear Society, Chicago, November 5-9 (1967).

10. GREEBLER, P., HUTCHINS, B.A., WOLFE, B., "Significance of Neutron Data to Fast Reactor Power Plant Design", Conference on Neutron Cross Section Technology, Washington, D. C., March 4-7 (1968).

11. KÜSTERS, H., SCHMIDT, J.J., BROEDERS, C.H.M., EISEMANN, E., METZENROTH, M., SCHROETER, K.E., THIEM, D., "Analysis of Fast Critical Assemblies and Large Fast Power Reactors with Group Constant Sets Recently Evaluated at Karlsruhe", KFK 793, Kernforschungszentrum, Karlsruhe, November (1968).

12. BROEDERS, C.H.M., "The Influence of Nuclear Data Uncertainties on Properties of Critical Assemblies", KFK 939, Kernforschungszentrum, Kar1sruhe, January (1969). 
13. SCHMIDT, J.J., "Current State of Phystcal knowiedge of the Most Important Reactor. Data", KFK 966, Kernforschungszentrum, Kar1sruhe, Apri1 (1969).

14. BARRE, J.Y., RAVIER, J., "Inaccuracies in the Characteristic Parameters of a Fast Power Reactor Due to the Prevailing Uncertainties in the Basic Neutron Data", Symposium on Fast Reactor Physics, Karlsruhe, October 30-November 3 (1967).

15. GANDINI, A., SALVATORES, M., DAL BANO, I., "Sensitivity Study of Fast Reactors Using Generalized Perturbation Techniques", Symposium on Fast Reactor Physics, Karlsruhe, October 30-November 3 (1967).

16. KALLFELZ, J.M., ZOLOTAR, B.A., SEHGAL, B.R., "Modifications to Fissile Element Cross Sections, and their Influence on Calculated Fast Reactor Parameters", Personal Communication, W. B. Loewenstein to P. Greebler, Argonne National Laboratory, December (1969).

17. PENNY, S.K., "The Thrust of Cross Section Data Requirements for Reactor Shielding Calculations", 1969 winter Meeting of American Nuclear Society, San Francisco, November 30-December 4 (1969).

18. GWIN, R., WESTON, L.W., deSAUSSURE, G., INGLE, R.W., TODD, J.H., GILLESPIE, F.E., HOCKENBURY, R.W., BLOCK, R.C., "Measurements of the Neutron Fission and Absorption Cross Section of ${ }^{239} \mathrm{Pu}$ Over the Energy Region 0.02 to $30 \mathrm{keV",} \mathrm{ORNL-TM-2598,} \mathrm{Oak} \mathrm{Ridge} \mathrm{National} \mathrm{Laboratory,}$ October 7 (1969).

19. CZIRR, J.B., LINDSEY, J.S., "A Measurement of the Capture to Fission Ratios for Pu-239", UCRL-72080, Lawrence Radiation Laboratory, Livermore, Callfornta, November (1969).

20. SHOMBERG, M.G., SOWERBY, M.G., BOYCE, D.A., MURRAY, K.J., SUTTON, D.L., "The Ratio of the Capture and Fission Cross-Sections of Pu-239 $\therefore$ the Energy Range $100 \mathrm{eV}$ to $30 \mathrm{keV}$ ", $\mathrm{CN}-26 / 33$, Second International Conference on Nuclear Data for Reactors, Helsinki, Finland, June (1970).

21. KATO, W.Y., ARMANI, R.J., LARSEN, R.P., MORELAIND, P.E., MOUNTFORD, L.A., GASIDLO, J.M., POPEK, R.J., SWANSON, C.D., "An Integral Measurement of $23{ }^{9} \mathrm{Pu}$ Alpha", 1970 Annual Meeting of American Nuclear Society, Los Angeles, June 28-July 2 (1970).

22. BRETSCHER, M.M., GASIDLO, J.M., REDMAN, W.C., "Comparison of Measured and Calculated Capture-to-Fission Ratios in a Soft Spectrum Fast Critical Assembly", 1970 Annual Meeting of American Nuclear Society, Los Angeles, June 28-July 2 (1970).

23. CAWTHORNE, C., FULTON, E.J., "Volds in Irradiated Stainless Steel"; Nature, Vol. 216, p. 57.5, November 11 (1967).

24. LAURITZEN, T., WOLFF, U.E., WITHOP, A., "Swelling of Anstenitic Stainless Steels", GEAP-13536, General Electric Co. (to be published). 
25. MOXON, M.C., "The Measurement of Average Neutron Capture Cross Sections In the Mass Region Above 100", Thesis Presented for Degree of M.Sc. to London University, Unpublished (1968).

26. MENLOVE, H.O. and POENITZ, W.P., "Absolute Radiative Capture Cross Section for Fast Neutrons in $238^{\prime \prime}$, Nuc. Sci. \& Engng. , 33, 24 (1968).

27. GLASS, N.W., SCHELBERG, A.D, TATRO, L.D., WARREN, J.H., "238U Neutron Capture Results from Bomb Source Neutrons", Conference on Neutron Cross Section Technology, Washington, D.C., March 4-7 (1968).

28. DAVEY, W.G., "Selected Cross Sections for ${ }^{232} \mathrm{Th},{ }^{233} \mathrm{U},{ }^{234} \mathrm{U},{ }^{235} \mathrm{U}$, ${ }^{236} \mathrm{U}, 2{ }^{37} \mathrm{~Np},{ }^{238} \mathrm{U}, 2{ }^{39} \mathrm{Pu}, 240 \mathrm{Pu}, 241 \mathrm{Pu}$ and $242 \mathrm{Pu} "$, Nuclear Science and Engineering, 32, p. 35-45, Apri1 (1968).

29. JAMES, G.D., PATRICK, B.H., "Evaluation of the ${ }^{239}$ Pu Fission Cross Section in the Energy Range $1 \mathrm{keV}$ to $100 \mathrm{keV}$ ", AERE-M2065 (Amended), AERE Harwell, October (1968).

30. HART, W., "Revised Fission Cross Section Evaluations for the Energy Range $1 \mathrm{keV}$ to $15 \mathrm{MeV}^{\prime \prime}$, AHSB(S)R169, AERE Risley, (1969).

31. DAVEY, W.G., "An Analysis of the Capture Cross Section of $238 \mathrm{U}$ Between $1 \mathrm{keV}$ and $15 \mathrm{MeV} "$, Nuc. Sci. \& Engng., 39, 337-360, March (1970).

32. PERING, N.C., LEWIS, T.A., "Performance of $140 \mathrm{MeV}$ High Current Short Pulse Linac at ORNL", Proc. of Particle Accelerator Conference, Washington., D.C., March 5-7 (1969).

33. MURPHY, P.M., "The Influence of Plutonium on the Design of Advanced Reactors", Twelf th Annual Meeting of American Nuclear Society, Denver, Colorado, June 20-23 (1966).

34. DIETRICH, R.J., "Uranium Requirements for Nuclear Power", Nuclear News, Vol. 10, no. 9, September (1967).

35. CRAMER, S.N., CAIN, V.R., STRAKER, E.A., "Monte Carlo Graphite BenchMark Calculations Using S Adjoint Biasing", 1969 Winter Meeting of the American Nuclear Soclety, ${ }^{n}$ San Francisco, November 30-December 4 (1969).

36. ZIMMERMANN, H., "Dose Rate of Reprocessed Na-1 Breeder Fue1", EURFNR-385, Kernforschungszentrum, Karlsruhe, July (1967).

37. BAILEY, H.S., EVATT, R.N., RUIZ, C.P., GYOREY, G.L., "Neutron Shielding Problems in High Burnup Thermal Reactor Fuel. Shipping", 1969 Winter Meeting of American Nuclear Society, San Francisco, November $30-$ December 4 (1969).

38. SNYDER, T.M., "Future Cross Section Needs of the Nuclear Power Industry", Conference on Neutron Cross Section Technology, Washington, D.C., March 22-24 (1966).

39. BELYAEV, F.N., IGNATEV, K.G., SUKHORUCHKIN, S.I., ET AL, "Measurement of the Ratio of the U-235 and Pu-239 Capture and Fission Cross Sections", $\mathrm{CN}-26 / 89$, Second International Conference on Nuclear Data for Reactors, Helsinki, Finland, June (1970). 
40. EVATT, R.N., HUTCHINS, B.A., "Derivation of $23{ }^{9} \mathrm{Pu}$ Resonance Parameters from Correlation of Experimental Data", 1969 Annual Meeting of American Nucle.ir Society, Seattle, June (1969).

41. SHUNK, E.R., BROWN, W.K., LaBAUVE, R., "Fission Cross Sections from Petre1", LA-3586, Los Alamos Scientific Laboratory, December (1966).

42. GILBOY, W.B., and KNOLL, G., "The Fission ross Sections of Some Plutonium Isotopes in the Neutron Energy Pange 5 to $150 \mathrm{keV",} \mathrm{KFK} 450$, Kernforschungszentrum, Karlsruhe (1966).

43. RYABOV, Y.V., et al, 'Measurement of the Radiative Capture and Fission Cross Section Ratios for $235 \mathrm{U}$ and $23{ }^{2} \mathrm{Pu}$ in Resonance-Neutron Energy Region", Atomnaya Energiya, 24, 4 (1968).

44. WHITE, P.H., ant WARNER, G.P., "The Fission Cross Sections of ${ }^{233} \mathrm{U},{ }^{234} \mathrm{U}$, ${ }^{236} \mathrm{U}, 238 \mathrm{U}$ and $\because{ }^{37} \mathrm{~Np},{ }^{239} \mathrm{Pu}, 240 \mathrm{Pu}, 241 \mathrm{Pu}$, Relative to that of $23 \mathrm{~J}$ for Neutrons in the Energy Range 1 to $14 \mathrm{MeV}^{\prime \prime}$, Journal of Nuclear Energy, $\underline{21}, 671$ (1967).

45. LEHTO, W.K.; "Fission Cross Section Ratio Measurements of $23 .{ }^{9} \mathrm{Pu}$ and $23^{3} \mathrm{U}$ to $235_{\mathrm{U}}$ from 0.24 to $24 \mathrm{keV",} \mathrm{Nuclear} \mathrm{Science} \mathrm{and} \mathrm{Engineering,}$ 39, 361-367, March (1970).

46. GREENE, N.M., LUCIUS, J.L., CRAVEN, C.W., Jr., "An Evaluation and Compilation of the Fission and Capture Cross Sections of ${ }^{239} \mathrm{Pu}$ in the Energy Range $25 \mathrm{keV}$ - $15 \mathrm{MeV}^{\prime \prime}$, ORNL-TM-2797, Oak Ridge National Laboratory, January (1970).

47. MACKLIN, R.L., PASMA, P.J., GIBBUNS, J.H., "Kesonance Neutron Capture and Transmission in Sulphur, Iron and Lead", Phys. Rev., 136, B695 (1964).

48. PANITKIN, YU.G., TOLSTIKOV, V.A., "Radiative Capture of Neutrons with Energies in the Range $0.024-0.15 \mathrm{MeV}$ by U-238 Nucle1", CN-26/77, Second International Conference on Nuclear Data for Reactors, Helsinki, Finland, June (1970).

49. STAVISSKII, R.Y., et ai, "Measurements of ${ }^{230} \mathrm{U}$ Neutron Capture Cross Sections in the keV Neutron Energy Range", $\mathrm{CN}-26 / 78$, Second International Conference on Nuclear Data for Reactors, Helsinki, Finland, June (1970).

50. FRICKE, M.P., et al., "Measurement of Cross Sections for the Radiative Capture of $1-\mathrm{keV}$ to $1-\mathrm{MeV}$ Neutrons by Mo, Rh, Gd, Ta, W, Re, An and $23{ }^{\prime \prime}{ }^{\prime \prime}, \mathrm{CN}-26 / 43$, Second International Conference on Nuclear Data for Reactors, Helsinki, Finland, June (1970).

51. SMITH, A.B., Argonne National Laboratory, Personal Communication, B. A. Zolotar, of ANL, with B. A. Hutchins, of GE, November (1969). 
52. BARNARD, E., FERGUSON, A.T.G., MCMURRAY, W.R., van HEERDEN, I.J.; "Scattering of Fast Neutrons by $238 \mathrm{U}$ ", International Conference on Study of Nuclear Structure with Neutrons, Antwerp, EANDC-50-S, P/26 (1965).

53. STEIN, W.E., SMITH, R.K., SMITH, H.L., "Relative Fission Cross Sections of $236 \mathrm{U}, 238 \mathrm{U}, 237^{7} \mathrm{~Np}$, and $238 \mathrm{U}$ ", Conference on Neutron Cross Section Technology, Washington, D. C., March 4-7 (1968):

54. BYERS, D.H., et al, "Fission Cross Sections from Petrel", LA-3586, Los Alamos Scientific Laboratory (1966).

55. BARNARD, E., DeVILLIERS, J.A.M., ENGELBRECHT, C.A., REITMAN, D., SMITH, A.B., "High Resolution Fast Neutron Cross Section of Iron", PEL 180, Pelindaba, Pretoria, July (1968).

56. CIERJACKS, S., FONTI, P., KOPSCH, D., KROPP, L., NEBE, J., UNSELD, H., "High Resolution Total Neutron Cross Sections Between 0.5 - 30 MeV", $^{\text {i", }}$ KFK 1000, Kernforschungszentrum, Karlsruhe, Junè. (1968).

57. CARLSON, A.D., CERBONE, R.J., WILLOUGHBY, D.F., "Measurement of Neutron. Penetration Standards. Volumn III. High Resolution Measurements of the Total Neutron Cross Sections of Nitrogen and Iron", GA-9149 (Vo1.2); Gulf General Atomic, Inc., March 27 (1969).

58. MEADOWS, J.W., WHALEN, J.F., "Energy Dependence of $\bar{v}$ for NeutronInduced Fission of $235 \mathrm{U}$ Below $1.0 \mathrm{MeV}$ ", Journal of P Puclear Energy, 21, p. 157, February (1967).

5.9. KUZNETSOV, V.F., SMIRENKIN, G.N., "The Average Number of Neutrons in the Fission of ${ }^{23}{ }^{3} \mathrm{U}$ and $235_{\mathrm{U}}$ by 0.08 - $1 \mathrm{MeV}$ Neutrons", Atomnaya. Energiya, 22, p. 401, May (1967).

60. SAVIN, M.V., KHOKHLOV, Ju. A., PARAMONSVA, I.N.; "The Average Number of Prompt Neutrons for. Fast Neutron Fission of U-235, Pu-239 and Pu-240", CN-26/40, Second International Conference on Nuclear Data for Reactors, Helsinki; Finland, June (1970):

61. VORSHEVA, V.G., et al., "Analysis of the Neutron Energy Dependence of $\bar{v}$ on the Basis of the Energy Balance in Nuclear Fission", CN-26/83, Second International Conference on Nuclear Data for keactors, Helsinki, Finland, June (1970):

62. KUZNETSOV, V.F., et a1., "Some Characteristics of the Process of Pu-239 Fission Induced by Fast Neutrons", $\mathrm{CN}-26 / 74$, Second International Conference on Nuclear Data for Reactors; Helsinki, Finland, June (1970).

63. SOLEILHAC, M.; FREHAUT, J., GUARIAAN, J.; MOSINSKI, M., "Measurement of the Mean Number of Prompt Neutrons and Relative Cross Sections for the Fission of $\mathrm{U}-235$ and $\mathrm{Pu}-239$ by Neutrons with Energies Between 0.3 and $1.4 \mathrm{MeV} ", \mathrm{CN}-26 / 67$, Second International Conference on Nuclear Data for Reactors, Helsink1; Finland, June (1970). 
64. GRUNDL, J.A., "A Study of Fission Neutron Spectra with High Energy Activation Detectors, Part II: Fission Spectra", Nuclear Science and Engineering, 31, 191-206, February (1968).

65. McELROY, W.N., "Implications of Recent Fission-Averaged Cross Section Measurements", Nuclear Sclence and Engineering, 36, 109-113, April (1969). 